\title{
The Nature of $\mathrm{Cu}_{\mathrm{A}}$ in Cytochrome $c$ Oxidase*
}

\begin{abstract}
Tom H. Stevens $\ddagger 8$, Craig T. Martin $\ddagger$, Hsin Wang, Gary W. Brudvig $\ddagger \rrbracket$, Charles P. Scholes $\|^{* *}$, and Sunney I. Chan

From the Arthur Amos Noyes Laboratory of Chemical Physics, California Institute of Technology, Pasadena, California 91125 and the ||Department of Physics and the Center for Biological Macromolecules, State University of New York at Albany, Albany, New York 12222
\end{abstract}

The isolation and purification of yeast cytochrome $c$ oxidase is described. Characterization of the purified protein indicates that it is spectroscopically identical with cytochrome $c$ oxidase isolated from beef heart. Preparations of isotopically substituted yeast cytochrome $c$ oxidase are obtained incorporating $\left[1,3-{ }^{15} \mathrm{~N}_{2}\right]$ histidine or $\left[\beta, \beta-{ }^{2} \mathrm{H}_{2}\right]$ cysteine. Electron paramagnetic resonance and electron nuclear double resonance spectra of the isotopically substituted proteins identify unambiguously at least 1 cysteine and 1 histidine as ligands to $\mathrm{Cu}_{\mathrm{A}}$ and suggest that substantial spin density is delocalized onto a cysteine sulfur in the oxidized protein to render the site $\mathrm{Cu}(\mathrm{I})-\mathbf{S}$.

When EPR spectra were first recorded from cytochrome $c$ oxidase, it was recognized that only one of the two coppers in the fully oxidized enzyme exhibited an EPR signal $(1,2)$. The observed EPR spectrum was not like those normally observed for $\mathrm{Cu}(\mathrm{II})$, however, and a number of explanations were forwarded. These included the proposal of an interaction between the two copper atoms in the enzyme, rendering a site with unusual EPR characteristics and only one-half the expected EPR intensity of two coppers (1). Subsequently it was shown $(3,4)$ that the EPR visible copper was an isolated $S=1 / 2$ site. Thus, the unusual EPR spectrum of the EPR visible copper (which will be referred to as the $\mathrm{Cu}_{\mathrm{A}}$ center) should be explained on the basis of the geometry and/or ligation of an isolated copper ion. A considerable interest in the structure of the $\mathrm{Cu}_{\mathrm{A}}$ center has derived from efforts to explain the unusual EPR properties of this site.

The EPR signal from the $\mathrm{Cu}_{\mathrm{A}}$ center is atypical of $\mathrm{Cu}(\mathrm{II})$ in

* This paper is Contribution 6444 from the Arthur Amos Nayes Laboratory of Chemical Physics, California Institute of Technology, Pasadena, CA 91125. The costs of publication of this article were defrayed in part by the payment of page charges. This article must therefore be hereby marked "advertisement" in accordance with 18 U.S.C. Section 1734 solely to indicate this fact.

$\ddagger$ Recipient of National Research Service Award 5T32GM-07616 from the National Institute of General Medical Sciences.

$\S$ Present address, Department of Biochemistry, University of California, Berkeley, California 94709.

If Present address, Department of Chemistry, Yale University, New Haven, Connecticut 06520.

** Recipient of Grant AM-17884 from the National Institute of Arthritis, Metabolism, and Digestive Diseases, United States Public Health Service, Grant RR07122 from the Biomedical Research Support Grant Program, Division of Research Resources, National Institutes of Health, and National Institutes of Health Research Career Development Award 1K04 AM-00274.

扭 Recipient of Grant GM-22432 from the National Institutes of General Medical Sciences and Biomedical Research Support Grant RR07003. To whom reprint requests should be sent. that no copper hyperfine splittings are clearly resolved and the $g$ values are quite small; in fact, one $g$ value is below the free electron $g$ value. Only two mechanisms, consistent with an isolated copper site, can be invoked to explain the unusual EPR properties. One possibility is that the unpaired electron spin resides primarily on an associated ligand (5-8). This mechanism calls for extensive charge delocalization from the involved associated ligand onto the copper ion. The $g$ values for the $\mathrm{Cu}_{\mathrm{A}}$ center are, in fact, typical of those in thiyl radicals, and it has been suggested that the $\mathrm{Cu}_{\mathrm{A}}$ center EPR signal might be due to a disulfide interacting with a copper ion (8) or due to a sulfur radical (5). A second possibility is that the orbital containing the unpaired electron is a hybrid $3 d$ copper orbital with strong admixtures of $4 s$ and $4 p$ character $(9,10)$. In this case, the unpaired electron would reside primarily on the copper. The unusual EPR properties would result from distorting the copper into a near tetrahedral geometry which allows mixing of copper $4 s$ and $4 p$ orbitals with the $3 d$ ground state.

With regard to the second possibility, a class of copper proteins is known in which the copper ion is forced into a distorted tetrahedral geometry. These copper sites are referred to as type 1 or blue coppers and have been extensively studied because they also exhibit unusual spectroscopic properties (11). In particular, the EPR spectra of type 1 coppers are unusual in that the copper hyperfine interaction is considerably reduced from that normally observed from $\mathrm{Cu}$ (II) complexes, although the $g$ values are normal. The optical spectrum, from which the name blue copper originated, also is unusual in that a very strong charge transfer absorption ( $\epsilon$ $\simeq 5000 \mathrm{M}^{-1} \mathrm{~cm}^{-1}$ ) is observed near $600 \mathrm{~nm}$. Normally, $\mathrm{Cu}(\mathrm{II})$ has only very weak absorption bands in the visible spectrum.

The $\mathrm{Cu}_{\mathrm{A}}$ center in cytochrome $c$ oxidase has been associated with the type 1 coppers for two reasons. First, the EPR spectrum of the $\mathrm{Cu}_{\mathrm{A}}$ center superficially resembles that of type 1 coppers; second, cytochrome $c$ oxidase has a very intense absorption near $600 \mathrm{~nm}$, part of which has been believed to be due to copper $(12,13)$. Therefore, if the unusual $\mathrm{EPR}$ properties of the $\mathrm{Cu}_{\mathrm{A}}$ center result from a distortion of the copper ion into a near tetrahedral geometry that allows mixing of $3 d, 4 s$, and $4 p$ orbitals, then type 1 coppers may be appropriate models for the $\mathrm{Cu}_{\mathrm{A}}$ center.

A number of studies have been carried out in which the $\mathrm{Cu}_{\mathrm{A}}$ center has been compared to type 1 coppers. The EPR parameters of the $\mathrm{Cu}_{\mathrm{A}}$ center were compared to those of the type 1 coppers (5). It was found that the type 1 coppers fall within a well defined region in a plot of $A_{\|}$versus $g_{\|}$, whereas the $\mathrm{Cu}_{\mathrm{A}}$ parameters were markedly different. Comparison of the x-ray absorption data on the $\mathrm{Cu}_{\mathrm{A}}$ center with those of the type 1 coppers plastocyanin (14) and stellacyanin (15) has also shown that the type 1 coppers do not closely resemble the $\mathrm{Cu}_{\mathrm{A}}$ 


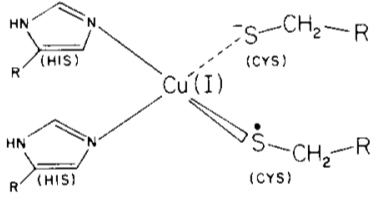

FIG. 1. Structure for the $\mathrm{Cu}_{\mathrm{A}}$ center in cytochrome $c$ oxidase proposed by Chan et al. $(6,7,16)$.

center. In particular, the x-ray absorption edge studies indicate that the type 1 copper in plastocyanin is in the cupric oxidation state when oxidized and in the cuprous oxidation state when reduced. However, the $\mathrm{x}$-ray absorption edge of the $\mathrm{Cu}_{\mathrm{A}}$ center does not change substantially upon reduction; in both the oxidized and reduced states the $\mathrm{Cu}_{\mathrm{A}}$ center appears as either a highly covalent $\mathrm{Cu}(\mathrm{II})$ or a $\mathrm{Cu}(\mathrm{I})$. Taken together, these results argue against a type 1 copper for the $\mathrm{Cu}_{\mathrm{A}}$ center. The unusual $g$ values and associated Cu hyperfine interaction observed by EPR, together with the absorption edge results obtained in $\mathrm{x}$-ray spectroscopy experiments, are in fact more indicative of a copper ion in a ligand environment where there has been considerable electron delocalization onto the copper from an associated ligand.

On the basis of the above considerations, sulfhydryl-binding experiments, and well known copper cysteine chemistry, we proposed some time ago $(6,7,16)$ that the $\mathrm{Cu}_{\mathrm{A}}$ center consisted of a $\mathrm{Cu}(\mathrm{I})$ ion ligated by two cysteine sulfurs, one a cysteinate and the other a sulfur radical, and two histidine nitrogens (Fig. 1). We have now undertaken experiments to test this model by incorporating cysteine substituted with ${ }^{2} \mathrm{H}$ at the methylene carbon $([2 \mathrm{H}] \mathrm{Cys})^{1}$ or histidine substituted with ${ }^{15} \mathrm{~N}$ at both imidazole ring positions $\left(\left[{ }^{15} \mathrm{~N}\right] \mathrm{His}\right)$ into yeast cytochrome $c$ oxidase. The EPR and ENDOR properties of these two samples of isotopically substituted cytochrome $c$ oxidase are described in this work. The results of these experiments together with the available physical data on this site will be discussed in the light of the model for the $\mathrm{Cu}_{\mathrm{A}}$ center shown in Fig. 1.

\section{MATERIALS AND METHODS}

All chemicals used in the enzyme purifications were of enzyme grade when available; otherwise, they were reagent grade. All the chemicals used in the growth of yeast such as vitamins, amino acids, and galactose were the highest grades available from Sigma. The [1,3${ }^{15} \mathrm{~N}_{2}$ ] histidine used for yeast growth was $95 \%{ }^{15} \mathrm{~N}$ in both histidine ring nitrogen positions and was obtained from Veb Berlin-Chemie, Berlin-Adlershof.

The $\left[\beta, \beta{ }^{2} \mathrm{H}_{2}\right]$ cysteine was synthesized according to the malonate condensation procedure of Crawhall and Elliot (17) as modified by Beilan (18) for use without the isolation and purification of intermediates. This procedure afforded the easiest approach to specific substitution at the $\beta$-carbon of cysteine. $\left[{ }^{2} \mathrm{H}_{2}\right]$ formaldehyde $\left(98 \%{ }^{2} \mathrm{H}_{2}\right.$, Stohler) was used to introduce the deuterated methylene group of the amino acid. The initial cysteine product was oxidized to cystine and then recrystallized. Immediately prior to use, the purified cystine was reduced to DL-cysteine with tin and $\mathrm{HCl}$.

\section{Preparation of the Yeast Enzyme}

Preparation and Isolation of Yeast Auxotrophs-The wild type Saccharomyces cerevisiae haploid strain D273-10B was mutagenized with ethylmethanesulfonate as described by Fink (19). Cells that grew on minimal medium plus cysteine were then checked for growth in the absence of cysteine. Colonies that proved to be cysteine auxotrophs were then finally checked for respiratory-deficient mutations, characteristic of "petite" mutants. Colonies that passed all the above tests were then stored on rich media at $4{ }^{\circ} \mathrm{C}$. Histidine auxotrophs

${ }^{1}$ The abbreviations used are: $\left[{ }^{2} \mathrm{H}\right] \mathrm{Cys},\left[\beta, \beta-{ }^{2} \mathrm{H}_{2}\right]$ cysteine; $\left[{ }^{15} \mathrm{~N}\right] \mathrm{His}$, $\left[1,3-{ }^{15} \mathrm{~N}_{2}\right]$ histidine; $\left[{ }^{2} \mathrm{H}\right] \mathrm{Cys}$ cytochrome $c$ oxidase, the protein specifically substituted with $\left[{ }^{2} \mathrm{H}\right] \mathrm{Cys} ;\left[{ }^{15} \mathrm{~N}\right] \mathrm{His}$ cytochrome $c$ oxidase, the protein specifically substituted with $\left[{ }^{15} \mathrm{~N}\right] \mathrm{His}$; ENDOR, electron nuclear double resonance. were isolated by the same procedure as outlined above except the supplemented nutrient was histidine. The cysteine and histidine auxotrophs were labeled $10 \mathrm{~B} \mathrm{Cys}{ }^{-}$and $10 \mathrm{~B} \mathrm{His}^{-}$, respectively.

Large Scale Yeast Growth-For the isolation of yeast mitochondria and cytochrome $c$ oxidase, the yeast cells were grown in a 350liter fermenter which was interfaced to a Sharples continuous flow centrifuge. For growth of the wild type yeast cells in the 350-liter fermenter, the media contained yeast nitrogen-base components (20), $1 \%$ galactose, $1 \mathrm{~kg}$ of casamino acids (Difco), $11 \mathrm{~g}$ each of uracil and adenine, $11 \mathrm{~g}$ of penicillin, and $17 \mathrm{~g}$ of streptomycin. In addition, $95 \%$ ethanol was added as an additional carbon source at a rate of about 1 gallon/day. A freshly grown yeast culture was used to inoculate the 350 -liter fermenter to a level of about $10^{6} \mathrm{cells} / \mathrm{ml}$, and growth was allowed to proceed to about $5 \times 10^{8}$ cells $/ \mathrm{ml}$. All yeast growth was carried out at $30^{\circ} \mathrm{C}$. The yield of yeast cells after 3 days of growth was about $5-6 \mathrm{~kg}$, wet weight.

The yeast auxotrophs were grown as described for the wild type cells except the media contained yeast nitrogen-base components, $1 \%$ galactose, $11 \mathrm{~g}$ of each uracil and adenine, $17 \mathrm{~g}$ of all $\mathrm{L}$-amino acids except either histidine or cysteine, $11 \mathrm{~g}$ of penicillin, and $17 \mathrm{~g}$ of streptomycin. In the case of the histidine auxotroph, $2 \mathrm{~g}$ of $\mathrm{DL}-[1,3-$ ${ }^{15} \mathrm{~N}_{2}$ ] histidine. $\mathrm{HCl}\left(95 \%{ }^{15} \mathrm{~N}_{2}\right)$ were added to the media. For the cysteine auxotroph, $6 \mathrm{~g}$ of DL- $\left[\beta, \beta-{ }^{2} \mathrm{H}_{2}\right]$ cysteine $\cdot \mathrm{HCl}\left(98 \%{ }^{2} \mathrm{H}_{2}\right)$ were added to the growth media. The starter cultures of the two auxotrophs used for inoculation produced starting cell densities of about $3 \times 10^{6}$ cells $/ \mathrm{ml}$. The cultures were allowed to grow for 2-3 days, with monitoring for revertants and contaminants every $12 \mathrm{~h}$. The cells were harvested when the increase in cell density began to level off $\left(\sim 3-5 \times 10^{7}\right.$ cells $\left./ \mathrm{ml}\right)$. At this point, a sample of the culture was removed to determine the level of revertants. For both the cysteine and histidine auxotrophs, the level of revertants at the completion of growth was less than $0.004 \%$.

Isolation of Yeast Mitochondria-Mitochondria were isolated from yeast by the method of Tzagoloff (21) as modified by Shakespeare and Mahler (22). The yeast cells were frozen in liquid nitrogen $(\sim 500 \mathrm{~g}$, wet weight) and transferred to a precooled 1-gallon steel Waring blender. This frozen pellet was blended on high speed until all chunks were reduced to a very fine powder. About $1,400 \mathrm{ml}$ of room temperature buffer, $0.4 \mathrm{M}$ sucrose, $50 \mathrm{~mm}$ Tris-acetate, $2 \mathrm{~mm}$ EDTA, pH 7.4, were added to the blender. This suspension was then blended for $2 \mathrm{~min}$ alternating between low and high speeds. After adjusting the $\mathrm{pH}$ to about 7.5 with $\mathrm{KOH}$, the suspension was centrifuged at $2,000 \times g$ for $15 \mathrm{~min}$. The supernatant was adjusted to $\mathrm{pH}$ 5.2 with acetic acid and centrifuged at $54,000 \times g$ for $30 \mathrm{~min}$, and the mitochondrial pellets were then resuspended in $50 \mathrm{~mm}$ phosphate, $1 \%$ $\mathrm{KCl}, 1 \mathrm{~mm}$ EDTA, $\mathrm{pH}$ 7.4. Since each liquid nitrogen treatment resulted in breakage of only between $15-20 \%$ of the yeast cells, this procedure was repeated until almost all cells were broken, as evidenced by the size of the light fluffy layer of broken cell debris in the $2,000 \times g$ pellet. The mitochondria were resuspended in the phosphate $/ \mathrm{KCl} / \mathrm{EDTA}$ buffer to a protein concentration of $20 \mathrm{mg} / \mathrm{ml}$, as determined by the method of Lowry et al. (23) and stored at $-85^{\circ} \mathrm{C}$ until use.

Isolation of Yeast Cytochrome c Oxidase-The isolated mitochondria at $20 \mathrm{mg} / \mathrm{ml}$ of protein concentration were solubilized by the slow addition of $3 \mathrm{mg}$ of cholate (Calbiochem A grade) $/ \mathrm{mg}$ of protein as a $20 \%$ solution. All steps in the isolation were carried out at $0-4{ }^{\circ} \mathrm{C}$. To this suspension was added $176 \mathrm{~g}$ of solid ammonium sulfate/liter (to $30 \%$ of saturation) with stirring. After ammonium sulfate addition, the $\mathrm{pH}$ was adjusted to 7.4 and the suspension stirred for $4 \mathrm{~h}$. This suspension was centrifuged at $27,000 \times g$ for $30 \mathrm{~min}$ and the supernatant brought to $45 \%$ of saturation with the addition of $94 \mathrm{~g}$ of solid ammonium sulfate/liter. After stirring for $15 \mathrm{~min}$, the suspension was centrifuged at $27,000 \times g$ for $20 \mathrm{~min}$. The pellets were resuspended in $15 \mathrm{ml} / \mathrm{g}$ of original mitochondrial protein with $0.25 \mathrm{M}$ sucrose, $50 \mathrm{~mm}$ Tris-acetate, $0.5 \%$ cholate, pH 7.4 buffer and adjusted to $28 \%$ of saturation with a saturated ammonium sulfate solution (saturated at $4{ }^{\circ} \mathrm{C}$ ). All subsequent additions of ammonium sulfate were from a saturated solution. This solution was stirred for $15 \mathrm{~min}$ followed by centrifugation at $27,000 \times g$ for $20 \mathrm{~min}$. The supernatant was adjusted to $39 \%$ of ammonium sulfate saturation followed by centrifugation at $27,000 \times g$ for $20 \mathrm{~min}$. These pellets were resuspended in $2 \mathrm{ml} / \mathrm{g}$ of original mitochondrial protein with $1 \%$ Tween-80, $20 \mathrm{~mm}$ phosphate, $1 \mathrm{~mm}$ EDTA, pH 7.0 buffer. This solution was then dialyzed for $24 \mathrm{~h}$ against a 100 -fold larger volume of $0.5 \%$ cholate, $10 \mathrm{~mm}$ Tris-acetate, $1 \mathrm{~mm}$ EDTA, $\mathrm{pH}$ 7.4. This dialysis resulted in some precipitation of protein which was removed by centrifugation at $200,000 \times g$ for 30 min. 
Finally, the clarified high speed supernatant was applied to a cytochrome $c$ affinity column $(1.5 \times 30 \mathrm{~cm}, 25-\mathrm{cm}$ bed height $)$ previously equilibrated with the above dialysis buffer. This cytochrome $c$ affinity column was prepared by linking $1 \mathrm{~g}$ of cytochrome $c$ (Sigma Type VI) to $15 \mathrm{~g}$ of CNBr-activated Sepharose 4B (Sigma) according to published procedures $(24,25)$. After all the green protein solution had passed onto the column, the column was washed first with $100 \mathrm{ml}$ of dialysis buffer followed by $100 \mathrm{ml}$ of dialysis buffer containing $2 \%$ cholate. Very little green color eluted with these wash buffers; it was mostly brownish gold proteins that eluted under these conditions. The cytochrome $c$ oxidase was eluted with $0.2 \mathrm{M} \mathrm{KCl}, 10 \mathrm{mM}$ Trisacetate, $1 \mathrm{mM}$ EDTA, pH 7.4 buffer which contained either $0.5 \%$ cholate or $0.5 \%$ Tween-20. The elution of protein from the cytochrome $c$-Sepharose 4B column was monitored continuously at $280 \mathrm{~nm}$ with a Gilson HM UV-Visible dual beam spectrophotometer. The eluted fractions were checked for cytochrome $c$ oxidase by measuring the absorbance difference between 603 and $630 \mathrm{~nm}$ in the presence of dithionite (26). The green fractions were collected, and cholate was added (as a $20 \%$ solution) to a final concentration of $1.5 \%$. This solution was brought to $25 \%$ ammonium sulfate saturation and centrifuged at $20,000 \times g$ for $10 \mathrm{~min}$. The supernatant was adjusted to $38 \%$ ammonium sulfate saturation, and the resulting pellet was readily dissolved in a small volume of $0.5 \%$ cholate or Tween-20 buffer. The protein solution was then stored at $-85^{\circ} \mathrm{C}$ until use.

\section{Protein Assays}

Protein concentrations were determined by the method of Lowry et al. (23). Heme a concentrations were determined by two methods: 1) pyridine hemochromogen assay (27), assuming an extinction coefficient of $26.0 \mathrm{~mm}^{-1} \mathrm{~cm}^{-1}$ at $587 \mathrm{~nm}$, and 2) the difference in absorbance between 603 and $630 \mathrm{~nm}$ after reduction with sodium dithionite (26), assuming an extinction coefficient of $16.5 \mathrm{~mm}^{-1} \mathrm{~cm}^{-1}$. The results from these two procedures are in good agreement. The activity of the cytochrome $c$ oxidase so isolated was measured polarographically with a YSI model 53 oxygen electrode in a $\mathrm{pH} 7.4$ medium containing $50 \mathrm{mM}$ phosphate buffer, $0.5 \%$ Tween $-80,0.2 \mathrm{mg} / \mathrm{ml}$ of cytochrome $c$, and $30 \mathrm{~mm}$ ascorbate at $30^{\circ} \mathrm{C}$.

Absorption spectra of yeast cytochrome $c$ oxidase were recorded on a Cary 219 spectrophotometer at room temperature. All EPR spectra were recorded at $10-20 \mathrm{~K}$ on a Varian E-line Century Series $\mathrm{X}$-band spectrometer equipped with an Air-Products Heli-Trans low temperature system.

\section{ENDOR Spectroscopy}

ENDOR spectra were recorded at SUNY, Albany, with a spectrometer described elsewhere $(28,29)$. Spectra were obtained at $2.1 \mathrm{~K}$ in the dispersion $\left(x^{\prime}\right)$ mode under rapid passage conditions with microwave powers of about 10 microwatts (30). The amplitude of the ENDOR radiofrequency was typically $0.5 \mathrm{G}$ peak to peak. Field modulation at $100 \mathrm{KHz}$ was used for detection. A peak to peak field modulation amplitude of the order of $5 \mathrm{G}$ is most effective in obtaining nitrogen and strongly coupled proton ENDOR; a modulation amplitude of the order of $0.5 \mathrm{G}$ is most effective in obtaining well resolved ENDOR spectra from the weakly coupled protons near the free proton frequency $(30)$.

\section{RESULTS}

\section{Purification and Characterization of Yeast Cytochrome c Oxidase}

The progress of a typical preparation of yeast cytochrome $c$ oxidase is summarized in Table I. We note a substantial enhancement in heme a content after the purification of the protein on the cytochrome $c$ affinity column $(24,25)$. Fig. 2 shows the specific affinity of this column toward yeast oxidase; here the elution profiles of protein and oxidase are compared. While a substantial amount of protein is eluted at low salt concentrations, most of the cytochrome oxidase elutes at higher $(0.2 \mathrm{M} \mathrm{KCl})$ salt concentrations. The final heme a content of $8.7 \mathrm{nmol}$ of heme a/mg of protein compares well with typical values of 9-11 reported for preparations of beef heart cytochrome $c$ oxidase. Although this ratio is a useful indicator of biochemical purity, a low number implying the presence of protein contaminants and a high number suggest-
TABLE I

Purification of yeast cytochrome c oxidase

\begin{tabular}{rcc}
$\begin{array}{c}\text { Total } \\
\text { protein }\end{array}$ & $\begin{array}{c}\text { Specific } \\
\text { activity }\end{array}$ & $\begin{array}{c}\text { Heme a/ } \\
\text { protein }\end{array}$ \\
\hline \multicolumn{1}{c}{$m \boldsymbol{n g o l ~} \mathrm{O}_{2} / m g /$} & sec & nmol/mg \\
18,800 & 1.04 & $\mathrm{ND}^{a}$ \\
2,200 & 4.96 & 0.48 \\
& & \\
680 & 2.62 & 0.96 \\
43 & 11.5 & 5.9 \\
& & \\
30 & 11.9 & 8.7
\end{tabular}

Mitochondrial particles

First ammonium sulfate fractionation ( 30 to $45 \%$ )

Second ammonium sulfate fractionation ( 28 to $39 \%$ )

Combined peak fractions of cytochrome oxidase with affinity column eluate

Purified yeast cytochrome $c$ oxidase

${ }^{a} \mathrm{ND}$, not determined.

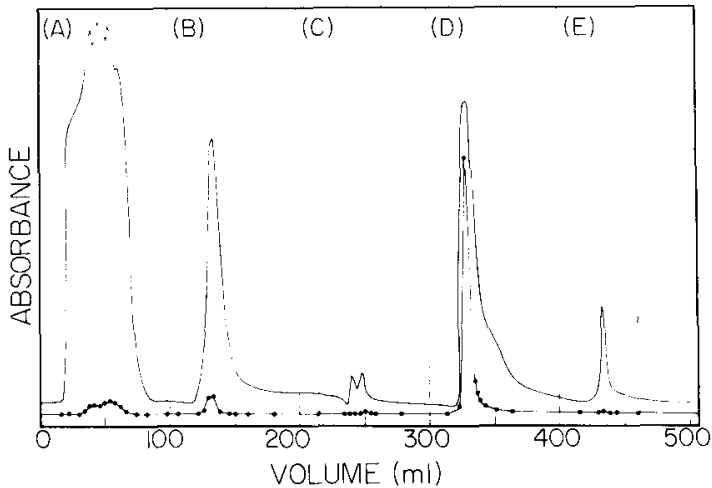

Fig. 2. Elution profiles of yeast cytochrome $c$ oxidase (bottom, solid circles) and total protein (top). Elution buffers were 10 $\mathrm{mm}$ Tris-acetate, $1 \mathrm{~mm}$ EDTA, pH 7.4, containing $0.5 \%$ cholate, $A ; 2 \%$ cholate, $B ; 0.5 \%$ Tween-20, $0.02 \mathrm{M} \mathrm{KCl}, C ; 0.5 \%$ Tween-20, $0.2 \mathrm{M} \mathrm{KCl}$, $D$; or $0.5 \%$ Tween- $20,1.0 \mathrm{M} \mathrm{KCl,} E$. Methods of monitoring concentrations of protein and yeast cytochrome $c$ oxidase are described in the text.

ing partial proteolysis or loss of subunits, the value to be expected for cytochrome $c$ oxidase based on the true molecular weight of the monomer is still not available for either the yeast or the beef heart protein (for a critical review, see Wikström et al. (31)).

Optical spectra of the yeast protein thus purified are shown in Fig. 3. These spectra reveal that this preparation of cytochrome $c$ oxidase is free of detectable contamination from cytochromes $b, c$ and $c_{1}$, as evidenced by the $A_{\text {red }}(602 \mathrm{~nm}) /$ $A_{\text {red }}(550 \mathrm{~nm})$ ratio of 2.4 . The $A_{\text {red }}(423 \mathrm{~nm}) / A_{\text {red }}(442 \mathrm{~nm})$ ratio is 0.40 , thus the amount of nonreducible oxidase (31) is low as well. Other relevant spectral ratios are: $A_{\text {red }}(442 \mathrm{~nm}) / A_{\text {ox }}(423$ $\mathrm{nm})=1.24$ and $A_{\text {red }}(602 \mathrm{~mm}) / A_{\text {ox }}(598 \mathrm{~nm})=2.09$. All ratios are close to the ratios reported by Lemberg for beef heart cytochrome $c$ oxidase (32).

Similarly the EPR spectrum of the purified yeast protein (Fig. 4) shows less than $1 \%$ high spin heme and no evidence of the adventitious copper or a contaminant signal around $g=$ 2 , which we have often seen in the spectra of the protein purified on the DEAE-column (33). Integrations of the EPR signals reveal a $\mathrm{Cu}_{\mathrm{A}}$ to cytochrome $a$ ratio of 0.81 , again very close to typical values reported for the beef heart protein. Thus, we conclude that the yeast cytochrome $c$ oxidase which we have isolated and purified compares favorably, on the basis of the spectroscopic criteria, with some of the best beef heart cytochrome $c$ oxidase preparations.

\section{EPR of Labeled Proteins}

The EPR spectra of native, $\left[{ }^{15} \mathrm{~N}\right] \mathrm{His}$, and $\left[{ }^{2} \mathrm{H}\right] \mathrm{Cys}$ yeast 


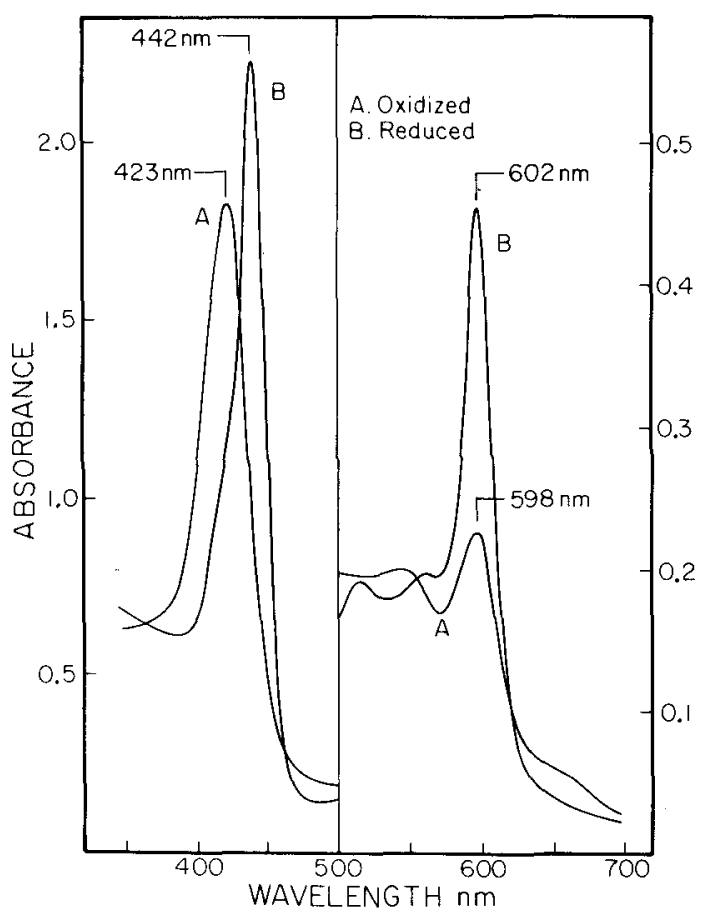

Fig. 3. Optical spectra of yeast cytochrome $c$ oxidase (21 $\mu \mathrm{M}) . A$, oxidized enzyme, $B$, enzyme reduced with $20 \mathrm{~mm}$ ascorbate and $0.2 \mathrm{~mm} p$-phenylenediamine.

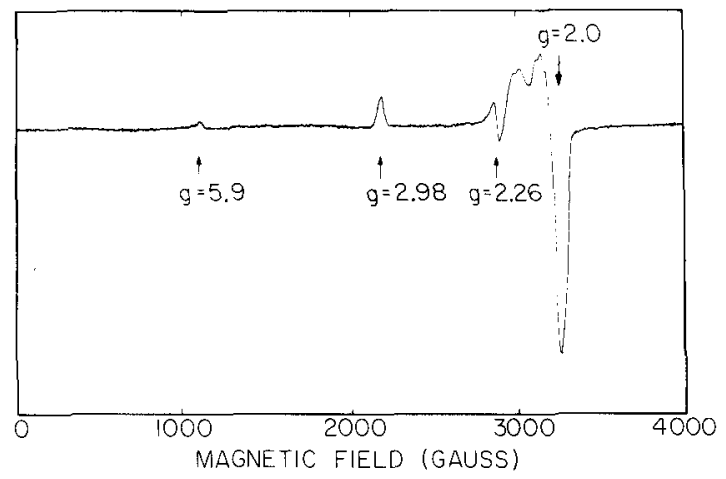

FIG. 4. EPR spectrum of yeast cytochrome $c$ oxidase. Conditions: temperature, $10 \mathrm{~K}$; microwave frequency, $9.10 \mathrm{GHz}$; microwave power, 0.02 milliwatt; modulation amplitude, $16 \mathrm{G}$.

cytochrome $c$ oxidase are compared in Fig. 5. The EPR spectra for both of the isotopically substituted proteins are qualitatively similar to the EPR spectrum of the native yeast protein. However, differences are noted in the $g=2$ region of the $\mathrm{Cu}_{\mathrm{A}}$ signal. The important observation is that this part of the $\mathrm{Cu}_{\mathrm{A}}$ signal has sharpened up somewhat for both of the isotopically substituted proteins, allowing the resolution of previously obscured hyperfine structure. This is most evident in the EPR spectrum of the $\left[{ }^{2} \mathrm{H}\right] \mathrm{Cys}$ protein; here, the hyperfine structure in the $g=2.03$ region, seen previously only at S-band (34), is almost completely resolved. We note that this structure, which has been assigned to a copper hyperfine interaction of $45 \mathrm{G}$ that is further split by interaction with either an $I=1 / 2$ nuclear or $S=1 / 2$ electron spin, remains unchanged on deuterium substitution of the cysteinyl $\beta$-protons. Thus, the spectral sharpening seen in the isotopically substituted proteins arises from the elimination or modification of smaller hyperfine couplings associated with the $\mathrm{Cu}_{\mathrm{A}}$ center, such as those reported in ENDOR studies on beef heart cytochrome $c$ oxidase (30).

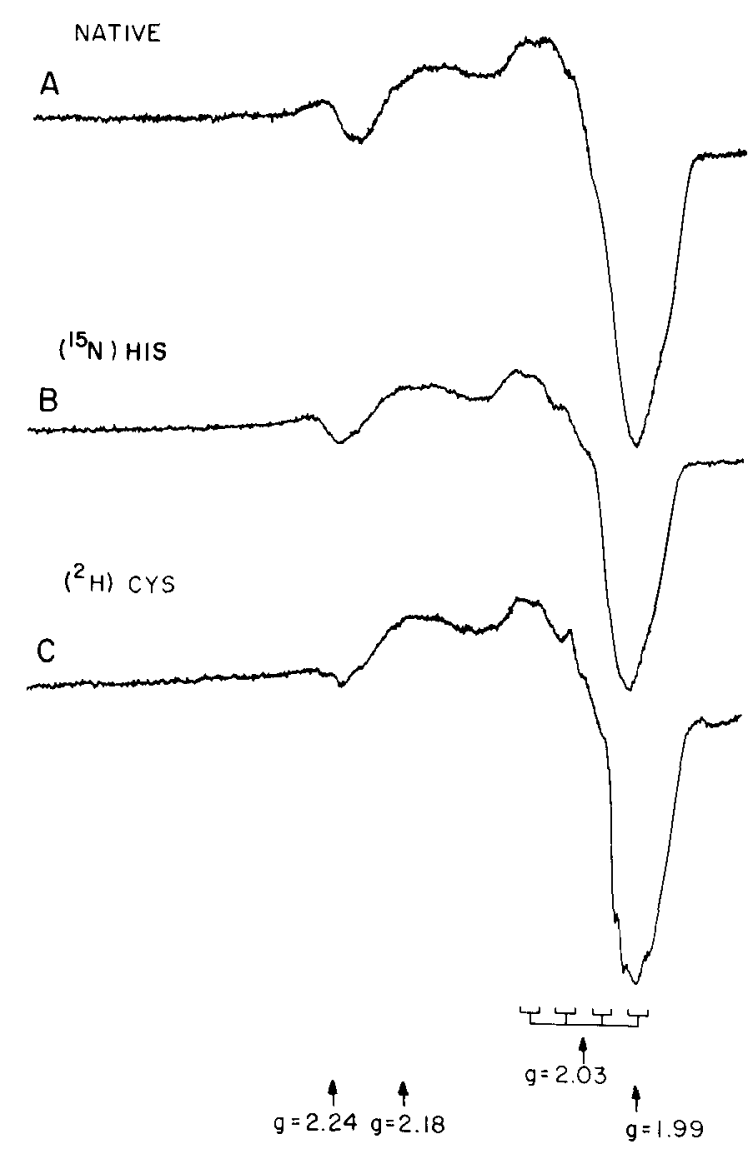

Fig. 5. EPR spectra of native, $A$; $\left[{ }^{15} \mathrm{~N}\right] \mathrm{His}, B$; and $\left[{ }^{2} \mathrm{H}\right] \mathrm{Cys}$ yeast cytochrome $c$ oxidase, $C$. Conditions: temperature, $15 \mathrm{~K}$; microwave frequency, $9.23 \mathrm{GHz}$; microwave power, 1.0 milliwatt; modulation amplitude, $16 \mathrm{G}$.

\section{ENDOR Studies of Yeast Cytochrome c Oxidase}

The $\mathrm{Cu}_{\mathrm{A}}$ ENDOR spectrum of native yeast cytochrome $c$ oxidase observed at $g=2.04$ with a modulation amplitude of $4.0 \mathrm{G}$ is shown in Fig. $6 A$. This spectrum is very similar to that of the beef heart protein. The two signals seen at 21.7 and $19.7 \mathrm{MHz}$ are due to strongly coupled protons and correspond to proton hyperfine couplings of 16.2 and $12.2 \mathrm{MHz}$, respectively. These proton couplings compare with couplings of 19.2 and $12.0 \mathrm{MHz}$ seen for the beef heart protein (30). The two signals seen at 7.1 and $9.2 \mathrm{MHz}$ are split by twice the characteristic ${ }^{14} \mathrm{~N}$ Zeeman energy $\left(2 \nu_{14_{\mathrm{N}}}=2.00 \mathrm{MHz}\right)$. They can accordingly be assigned to a ${ }^{14} \mathrm{~N}$ hyperfine coupling of 16 $\mathrm{MHz}$. A similar nitrogen coupling of $17 \mathrm{MHz}$ is seen for the beef heart protein. ENDOR spectra taken at $g=2.00$ and $g$ $=2.10$ (not shown) confirm that, as in the beef heart protein, both the nitrogen and the proton couplings are isotropic.

ENDOR spectra of isotopically substituted and native yeast cytochrome $c$ oxidase are compared at two different modulation amplitudes in Fig. 6. Note that due to the availability of only small amounts of isotopically substituted proteins having approximately 2 orders of magnitude fewer spins than the beef heart samples of Ref. 30 , it was necessary to make use of extensive signal averaging and moderately high modulation amplitudes in order to obtain spectra with reasonable signal to noise. The amplitude of the field modulation can affect the line shapes and intensities of ENDOR peaks differently (28). In order to ensure that our conclusions are independent of field modulation, we present in Fig. 6 ENDOR spectra taken at field modulation amplitudes of 4.0 and $6.4 \mathrm{G}$. Note that comparisons should only be made between spectra obtained 

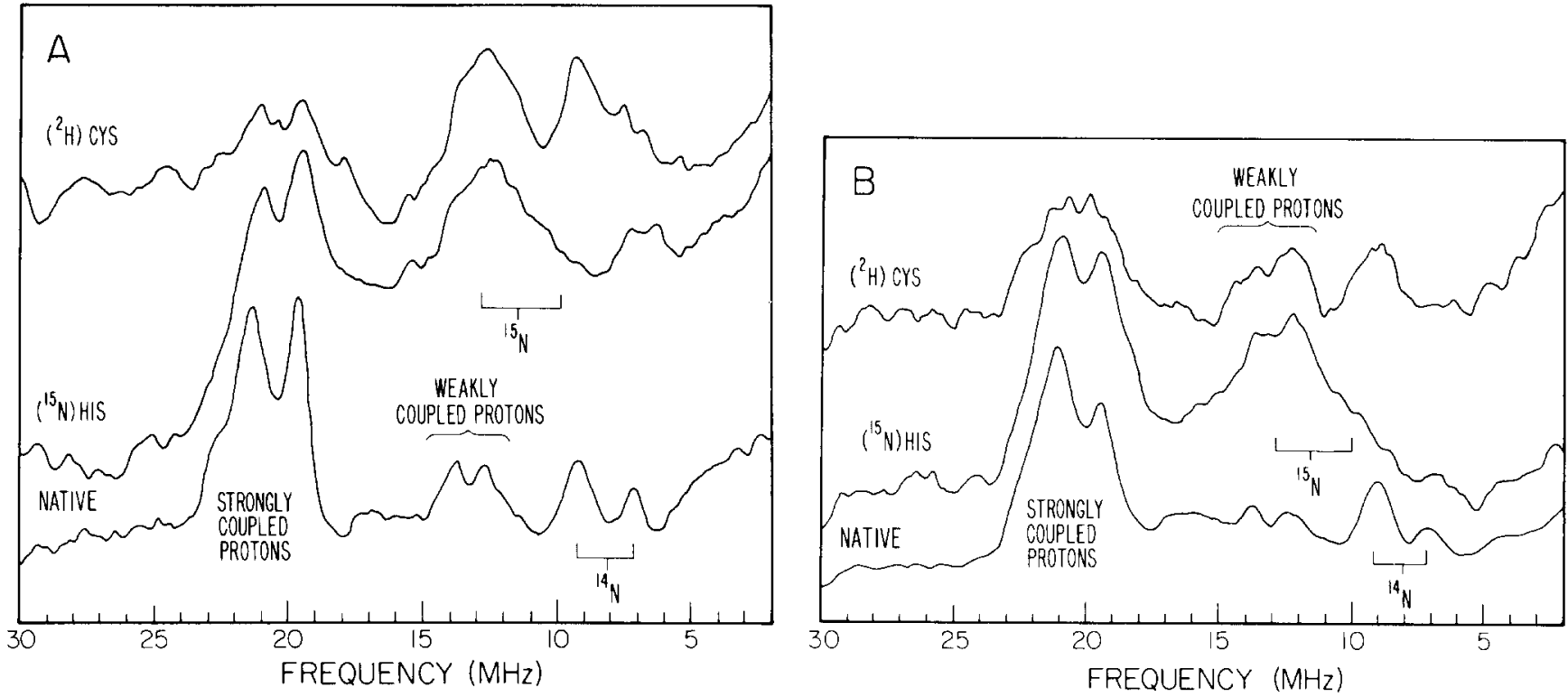

Fig. 6. ENDOR spectra of native, $\left[{ }^{15} \mathrm{~N}\right] \mathrm{His}$, and $\left[{ }^{2} \mathrm{H}\right] \mathrm{Cys}$ yeast cytochrome $c$ oxidase observed at $\boldsymbol{g}=2.04$ using two field modulations. $A, 4.0 \mathrm{G} ; B, 6.4 \mathrm{G}$. Conditions: temperature, $2.1 \mathrm{~K}$; microwave frequency, $9.12 \mathrm{GHz}$; microwave power, 10 microwatts; sweep rate, $3.1 \mathrm{MHz} / \mathrm{sec}$. In $A$ the instrumental time constants for native, $\left[{ }^{15} \mathrm{~N}\right] \mathrm{His}$, and $\left[{ }^{2} \mathrm{H}\right] \mathrm{Cys}$ were $0.05,0.10$, and $0.15 \mathrm{~s}$, respectively; and in $B$ it was $0.10 \mathrm{~s}$ throughout.

with the same field modulation amplitude.

$\left[{ }^{2} \mathrm{H}\right] \mathrm{Cys}$ Substituted Protein-Comparison of the $\left[{ }^{2} \mathrm{H}\right] \mathrm{Cys}-$ substituted and native protein ENDOR spectra in Fig. 6 reveals a significant change in the $18-24 \mathrm{MHz}$ region. As approximate indicators of intensity for changes in the 18-24 $\mathrm{MHz}$ region, we have used internal comparisons with the ${ }^{14} \mathrm{~N}$ ENDOR resonance at $9 \mathrm{MHz}$ and with the weakly coupled proton ENDOR resonances near $14 \mathrm{MHz}$. Both methods indicate that the intensity of the signals in the $18-24 \mathrm{MHz}$ region decreases by more than $50 \%$ on substitution of $\left[{ }^{2} \mathrm{H}\right] \mathrm{Cys}$ for native cysteine in the yeast protein. We note that within the signal to noise, the line shapes in this region of the ENDOR spectra appear qualitatively different between the $\left[{ }^{2} \mathrm{H}\right]$ Cys protein and the native protein, suggesting that there may be other interfering signals here. If this is the case, the strongly coupled protons have decreased in intensity by more than $50 \%$ upon deuterium substitution. Unfortunately, the small deuteron nuclear magnetic moment precludes observation of the deuterium ENDOR directly (1-3 $\mathrm{MHz}$ region). In any case, these ENDOR results together with the EPR data presented earlier demonstrate unambiguously that there is at least 1 cysteine ligand associated with $\mathrm{Cu}_{\mathrm{A}}$.

In order to ascertain whether there are weaker proton hyperfine interactions from cysteines associated with $\mathrm{Cu}_{\mathrm{A}}$, we have compared in Fig. 7 the ENDOR spectra between native and $\left[{ }^{2} \mathrm{H}\right] \mathrm{Cys}$ cytochrome $c$ oxidase in the region of the weakly coupled protons. It appears that there are no detectable changes in this region when $\left[{ }^{2} \mathrm{H}\right] \mathrm{Cys}$ is substituted for native cysteine in the yeast protein, although the signal to noise may not allow us to rule out this possibility completely.

$\left[{ }^{15}\right.$ NJHis Substituted Protein. Upon comparison of the $\left[{ }^{15} \mathrm{~N}\right] \mathrm{His}$ and native protein ENDOR spectra (Fig. 6), we see that only the intensities of the ${ }^{14} \mathrm{~N}$ ENDOR signals at 7 and $9 \mathrm{MHz}$ are substantially reduced in the spectrum of the $\left[{ }^{15} \mathrm{~N}\right]$ His protein relative to that of the native protein. Due to the difference in the nuclear magnetic moments between the two nitrogen isotopes, substitution of the ${ }^{14} \mathrm{~N}$ nucleus by ${ }^{15} \mathrm{~N}$ would replace the ${ }^{14} \mathrm{~N}$ ENDOR signals at 7 and $9 \mathrm{MHz}$ by ${ }^{15} \mathrm{~N}$ ENDOR signals at 10 and $13 \mathrm{MHz}$, respectively. We do, in fact, observe increased intensity in the weakly coupled proton region in the ENDOR spectrum of the $\left[{ }^{15} \mathrm{~N}\right] \mathrm{His}$ protein,

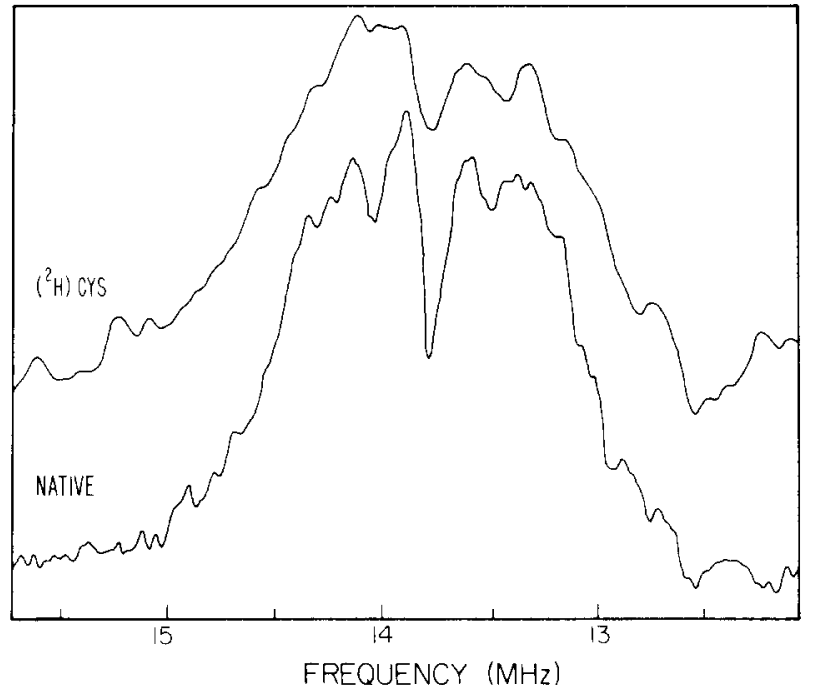

FIG. 7. ENDOR spectrum showing the weakly coupled proton region of native and $\left[{ }^{2} \mathrm{H}\right] \mathrm{Cys}$ yeast cytochrome $c$ oxidase observed at $\boldsymbol{g}=2.00$ using a field modulation of $0.5 \mathrm{G}$. Conditions are as in Fig. 6 except that the sweep rate was $0.4 \mathrm{MHz} / \mathrm{sec}$ and time constants were 0.05 and $0.10 \mathrm{~s}$ for native and $\left[{ }^{2} \mathrm{H}\right] \mathrm{Cys}$ proteins, respectively.

consistent with the appearance of resonances at 10 and 13 $\mathrm{MHz}$. From these observations, it is clear that there is at least 1 histidine ligand to $\mathrm{Cu}_{\mathrm{A}}$ in cytochrome $c$ oxidase.

\section{DISCUSSION}

In this paper we report the successful isolation and purification of cytochrome $c$ oxidase from the yeast $S$. cerevisiae. The protein thus isolated is shown to have spectroscopic properties very similar to those of cytochrome $c$ oxidase isolated from beef heart, suggesting that the active sites of the two proteins are identical. Inasmuch as the yeast system can be manipulated to provide direct incorporation of isotopically substituted amino acids, we have used this system to probe the structure of the metal centers of this protein by preparing 
$\left[{ }^{2} \mathrm{H}\right] \mathrm{Cys}$ - and $\left[{ }^{15} \mathrm{~N}\right] \mathrm{His}$-substituted cytochrome $c$ oxidase. These studies, together with those described in a recent report (35), represent the first concrete information regarding the ligands to the metal centers in cytochrome $c$ oxidase.

\section{Analysis of EPR Spectra}

The X-band EPR spectra of the $\left[{ }^{15} \mathrm{~N}\right]$ His and $\left[{ }^{2} \mathrm{H}\right] \mathrm{Cys}$ proteins are very similar to those of the native protein, the only difference being that in the spectra of the isotopically substituted proteins, there is some narrowing of the spectral components that make up the region around $g=2$. In the case of the $\left[{ }^{15} \mathrm{~N}\right]$ His protein, substitution of ${ }^{15} \mathrm{~N}$ for ${ }^{14} \mathrm{~N}$ at both histidine ring positions results in some spectral sharpening in this region. Assuming the dominant nitrogen interaction is the 17-MHz hyperfine seen in the ENDOR spectrum of the native protein, substitution of $\left[{ }^{15} \mathrm{~N}\right] \mathrm{His}$ would result in a reduction in the overall splitting from the $I=1{ }^{14} \mathrm{~N}$ nucleus of $34 \mathrm{MHz}(2 A$ $=12 \mathrm{G})$ to $24 \mathrm{MHz}(A=8.6 \mathrm{G})$ for the $I=1 / 2{ }^{15} \mathrm{~N}$ nucleus. The sharpening of spectral features in the $\mathrm{Cu}_{\mathrm{A}}$ signal (Fig. $5 B$ ) is consistent with at least this change in hyperfine interaction, although it is possible that there are other (smaller) nitrogen couplings from histidine ligands that are also modified upon this isotopic substitution.

Similarly, the substitution of ${ }^{2} \mathrm{H}$ for ${ }^{1} \mathrm{H}$ at the methylene carbon of cysteine eliminates the proton hyperfine interactions from the methylene protons of cysteine and results in some sharpening of the spectral components around $g=2$. This permits the resolution of hyperfine structure not seen previously in the X-band spectrum. This EPR spectrum of the $\left[{ }^{2} \mathrm{H}\right]$ Cys protein may be compared with the S-band $(2-4$ GHz) EPR spectrum of beef heart cytochrome $c$ oxidase which was recently reported (34). The latter spectrum shows a resolved eight-line hyperfine pattern along $g_{y}=2.03$. The splittings observed for the $\left[{ }^{2} \mathrm{H}\right] \mathrm{Cys}$ protein at X-band can, in fact, be fitted to this eight-line hyperfine pattern very well. The eight-line pattern observed in the S-band EPR spectrum was interpreted in terms of a $45 \mathrm{G}$ copper hyperfine interaction $(I=3 / 2)$ and an additional $25 \mathrm{G}$ interaction with either an $I$ $=1 / 2$ or an $S=1 / 2$ spin. Inasmuch as the substitution of deuterons for the methylene protons in cysteine does not alter the observed eight-line hyperfine pattern, specifically, substitution does not eliminate the $25 \mathrm{G}$ interaction but merely allows it to be resolved at $\mathrm{X}$-band, we can rule out the cysteinyl methylene protons as the origin of a possible $25 \mathrm{G}$ proton $(I=1 / 2)$ hyperfine interaction.

A dipolar interaction between $\mathrm{Cu}_{\mathrm{A}}$ and cytochrome $a(S=$ $1 / 2$ ) has been proposed by Greenaway et $a l$. (9) and by Froncisz et al. (34) which could lead to a dipolar splitting of the $\mathrm{Cu}_{\mathrm{A}}$ signal of the order of $25 \mathrm{G}(36)$. The manifestation of such a static dipolar splitting would be strongly temperaturedependent and would occur only at low temperatures when the relaxation of cytochrome $a$ is sufficiently slow. Accordingly, we have studied the temperature dependence (10-95 K) of this splitting in the X-band EPR spectra of $\left[{ }^{2} \mathrm{H}\right] \mathrm{Cys}$ cytochrome $c$ oxidase. We have observed no change in the $\mathrm{Cu}_{\mathrm{A}}$ hyperfine pattern even at temperatures as high as $95 \mathrm{~K}$, at which temperatures the cytochrome $a$ signal at $g \simeq 3$ is broadened almost beyond detection due to rapid relaxation of the heme center. Scholes et $a l^{2}{ }^{2}$ have also noted that the splitting observed in the S-band EPR spectrum of beef heart cytochrome $c$ oxidase remains unchanged at temperatures as high as $77 \mathrm{~K}$. These results argue against a dipolar interaction between $\mathrm{Cu}_{\mathrm{A}}$ and cytochrome $a$ as the origin of the 25-G interaction. The nature of this interaction thus remains elusive.

${ }^{2}$ C. P. Scholes, W. Froncisz, and J. S. Hyde, private communication.
It is well known that, even for the best preparations of beef heart cytochrome $c$ oxidase where the stoichiometric copper to iron molar ratio has been established to be unity, the total measured integrated intensity of the EPR signal from $\mathrm{Cu}_{\mathrm{A}}$ is only $80 \%$ of that expected from the integrated intensity of the cytochrome a EPR signal (37). We have obtained the same result for the yeast protein. No satisfactory explanation of this $\mathrm{Cu}_{\mathrm{A}}$ EPR intensity anomaly has yet been offered; it seems possible, however, that the apparent reduced intensity of the $\mathrm{Cu}_{\mathrm{A}}$ EPR signal may arise from anisotropic spectral broadening resulting from magnetic interaction of $\mathrm{Cu}_{\mathrm{A}}$ with another paramagnetic center in the protein, e.g. cytochrome $a$.

\section{Analysis of ENDOR Spectra}

Comparison of the ENDOR spectra of native, $\left[{ }^{2} \mathrm{H}\right] \mathrm{Cys}$, and $\left[{ }^{15} \mathrm{~N}\right]$ His cytochrome $c$ oxidase reveals even more clearly that there is at least 1 cysteine and 1 histidine as ligands to $\mathrm{Cu}_{\mathrm{A}}$.

$\left[{ }^{15} \mathrm{~N} J\right.$ His-substituted Protein-The assignment of a 16 $\mathrm{MHz}$ coupling to ${ }^{14} \mathrm{~N}$ of a histidine in the native protein is confirmed by the observed changes in the $7-15 \mathrm{MHz}$ region on substitution of $\left[{ }^{15} \mathrm{~N}\right] \mathrm{His}$ for $\left[{ }^{14} \mathrm{~N}\right] \mathrm{His}$ in cytochrome $c$ oxidase. Although the signal to noise of the ENDOR spectrum of the $\left[{ }^{15} \mathrm{~N}\right] \mathrm{His}$ protein is low, two observations are unambiguous: 1) the strong peak at $9 \mathrm{MHz}$ is no longer present in the spectrum of the $\left[{ }^{15} \mathrm{~N}\right] \mathrm{His}$ protein; and 2) the changes in intensity and line shape of the $10-15-\mathrm{MHz}$ region are consistent with two new signals arising from ${ }^{15} \mathrm{~N}$ substitution. There appear to be no other ENDOR signals that might be ascribed to histidine ring nitrogens. It is interesting to note that a hyperfine coupling of $16-17 \mathrm{MHz}$ is unusually low for a histidine nitrogen ligand to $\mathrm{Cu}(\mathrm{II})(38,39)$. However, it is not unexpected for a system where there has been a large delocalization of unpaired spin from $\mathrm{Cu}$ to a sulfur ligand.

$\left[{ }^{2} \mathrm{H}\right] \mathrm{Cys}$-substituted Protein-The existence of at least 1 cysteine as a ligand to $\mathrm{Cu}_{\mathrm{A}}$ is clearly demonstrated by the ENDOR of $\left[{ }^{2} \mathbf{H}\right]$ Cys-substituted cytochrome $c$ oxidase. The two resonances seen at 19.7 and $21.7 \mathrm{MHz}$ decrease in intensity by greater than $50 \%$ on substitution of $\left[{ }^{2} \mathrm{H}\right] \mathrm{Cys}$ for native cysteine. The incomplete elimination of intensity in this region can be rationalized as follows. It is possible that some proton exchange may have occurred at the methylene carbon during the biosynthesis of the enzyme. Alternatively, there may exist other signals in this region which obscure the actual decrease in intensity of the signals due to the strongly coupled protons from the cysteine. This second possibility raises the question of what other centers could give rise to ENDOR signals in this region. The presence of a distinct shoulder at $24 \mathrm{MHz}$ in the ENDOR spectrum of native, $\left[{ }^{2} \mathrm{H}\right] \mathrm{Cys}$, and $\left[{ }^{15} \mathrm{~N}\right] \mathrm{His}$ cytochrome $c$ oxidase indicates that this signal could not be due to hyperfine from a second histidine nitrogen or associated with methylene protens of a cysteine ligand to $\mathrm{Cu}_{\mathrm{A}}$. We plan further study on this signal, particularly with respect to its field dependence, so as to ascertain its identity.

The observed proton hyperfine couplings of 16 and $12 \mathrm{MHz}$ (19 and $12 \mathrm{MHz}$ for the beef heart protein) from the cysteinyl methylene protons can be interpreted in two ways. The couplings may arise from two methylene protons on the same cysteine, or alternatively, they may be due to two methylene protons on two different cysteine ligands. Proton hyperfine interactions from methylene protons adjacent to a sulfur radical arise from hyperconjugation (40). They are essentially isotropic and their magnitude depends on the dihedral angle, $\phi$, between the sulfur $3 p_{z}$ orbital containing the unpaired electron and the $\mathrm{C}-\mathrm{H}$ bond (41). The two isotropic proton coupling constants are given by

$$
A_{1}=A_{0} \rho \mathrm{s}^{\pi} \cos ^{2} \phi
$$




$$
A_{2}=A_{0} \rho_{\mathrm{S}^{\pi}} \cos ^{2}\left(\phi-125^{\circ}\right)
$$

where $A_{0}$ is a constant $\left(A_{0}=88 \mathrm{MHz}\right.$ for the $N$-acetyl-Lcysteine neutral sulfur radical (41)) and $\rho_{\mathrm{S}}{ }^{\pi}$ is the $\pi$-spin density on the sulfur. Knowing $A_{1}$ and $A_{2}$ for a given sulfur center, one can then solve for $\rho_{\mathrm{S}}{ }^{\pi}$ and the dihedral angle $\phi$.

If we assume that the methylene proton hyperfine values of 12 and $19 \mathrm{MHz}$ observed for the beef heart protein arise from protons on two different cysteine ligands to $\mathrm{Cu}_{\mathrm{A}}$, a range of angles may be chosen such that the other proton on each methylene carbon exhibits a negligible (less than $3 \mathrm{MHz}$ ) hyperfine coupling. For this situation, one cysteine sulfur can be assigned an unpaired spin density $\left(\rho_{\mathrm{S}}{ }^{\pi}\right)$ ranging from 0.14 to 0.37 , while the other cysteine sulfur will have a spin density ranging from 0.23 to 0.52 .

A simpler situation is that the hyperfine couplings of 12 and $19 \mathrm{MHz}$ arise from protons on the same cysteine ligand. In this case, only two distinct solutions are possible. In one, $\phi=$ $164^{\circ}$ and $\rho \mathrm{s}^{\pi}=0.23$; and in the other, $\phi=60^{\circ}$ and $\rho_{\mathrm{s}}{ }^{\pi}=0.83$. The latter solution is more in agreement with other spectroscopic data on the $\mathrm{Cu}_{\mathrm{A}}$ site as will be discussed in the next section. It is important to note that the assignment of the strong proton hyperfine couplings to methylene protons on the same cysteine ligand does not preclude the existence of a second cysteine ligand to $\mathrm{Cu}_{A}$. In fact, if $\rho_{\mathrm{S}}{ }^{\pi}$ is as high as 0.83 , a second cysteine ligand is necessary (6) to facilitate this large delocalization of spin from copper to the first cysteine (i.e. a delocalization of charge from cysteine to copper). If this were so, the magnitude of the hyperfine coupling to these more distant protons would be expected to be very small.

\section{A Model for the $\mathrm{Cu}_{\mathrm{A}}$ Site}

The incorporation of $\left[{ }^{15} \mathrm{~N}\right] \mathrm{His}$ and $\left[{ }^{2} \mathrm{H}\right] \mathrm{Cys}$ into yeast cytochrome $c$ oxidase has clearly shown the existence of at least 1 histidine and 1 cysteine as ligands to $\mathrm{Cu}_{\mathrm{A}}$. Furthermore, our ENDOR measurements on the $\left[{ }^{2} \mathrm{H}\right] \mathrm{Cys}$-substituted protein suggest that there is substantial spin delocalization onto a cysteinyl sulfur ligand. We will now examine these results, along with EPR and other pertinent physical data amassed on the $\mathrm{Cu}_{\mathrm{A}}$ site, and show how these data can be rationalized in terms of the model (Fig. 1) proposed for the site by Chan et $a l .(6,7,16)$.

The EPR spectrum for $\mathrm{Cu}_{\mathrm{A}}$ is unique with respect to other copper complexes in that one of its $g$ values is less than that of the free electron. It is important to note that $\mathrm{Cu}(\mathrm{II})$ complexes always exhibit $g$ values greater than or equal to the free electron $g$ value because the spin-orbit coupling parameter is negative for a $3 d^{9}$ system (42). In order to observe $g$ values less than the free electron $g$ value, it is necessary to mix the $3 d$ orbital containing the unpaired electron with an orbital that will exert a positive spin-orbit coupling. There are only two reasonable possibilities: either the $3 d$ orbital is mixed with the $4 p$ orbital of copper $(9,10)$ or it is mixed with an orbital of an associated sulfur ligand (5-8).

Similarly, the observed copper hyperfine values for the $\mathrm{Cu}_{\mathrm{A}}$ center are unique among $\mathrm{Cu}$ (II) complexes. Recent ENDOR studies have revealed a small copper hyperfine interaction associated with the $\mathrm{Cu}_{\mathrm{A}}$ center, but this copper hyperfine interaction is small and nearly isotropic (10) $\left(\left|A_{x}\right|=68 \mathrm{MHz}\right.$, $\left|A_{y}\right|=98 \mathrm{MHz},\left|A_{z}\right|=90 \mathrm{MHz}$ ). As discussed recently (16), this unusually isotropic copper hyperfine interaction for the $\mathrm{Cu}_{\mathrm{A}}$ center indicates that the distributed dipole interaction between the unpaired electron and the copper nucleus is small. A number of investigators have invoked the mixing of a copper $4 p$ orbital with the $3 d$ orbital in order to reduce the distributed dipole interaction $(9,10)$. However, recent calculations have shown that in order to eliminate the anisotropic copper hyperfine interaction, it is necessary to include about 3 times as much $4 p$ character as $3 d_{x^{2}-y^{2}}$ or $3 d_{x y}$ character (16). We feel that such a large mixing is unreasonable in view of the fact that the $3 d^{8} 4 p$ configuration lies about $125,000 \mathrm{~cm}^{-1}$ above the $3 d^{9}$ configuration for divalent copper (14). Another way to reduce the distributed dipole interaction of the electron spin with the copper nucleus is the delocalization of the unpaired electron spin density onto an associated ligand sufficiently removed from the copper ion, i.e. onto an associated sulfur ligand.

Extensive delocalization of spin onto sulfur in the oxidized state would predict that copper remains mainly in the cuprous state both in the oxidized and the reduced forms of the $\mathrm{Cu}_{\mathrm{A}}$ center. X-ray absorption edge data from the $\mathrm{Cu}_{\mathrm{A}}$ center in both the oxidized and reduced forms appear to be consistent with this prediction $(14,15)$. These studies indicate that $\mathrm{Cu}_{\mathrm{A}}$ is either a $\mathrm{Cu}(\mathrm{I})$ or a very covalent $\mathrm{Cu}$ (II) in the oxidized protein. More important, the energy of the $1 s-4 s$ transition of $\mathrm{Cu}_{\mathrm{A}}$ does not change substantially when the enzyme is reduced. This latter finding is readily rationalized in terms of our model since, upon reduction, an associated ligand would be the actual electron acceptor, rather than the $\mathrm{Cu}$ ion itself.

Recently, extended $\mathrm{x}$-ray absorption fine structure experiments have been undertaken on the copper $K$ absorption edge of cytochrome $c$ oxidase. The preliminary results (43) suggest that two sulfur atoms are associated with $\mathrm{Cu}_{\mathrm{A}}$. In the oxidized enzyme, the smaller copper-sulfur distance is $2.27 \AA$. When the enzyme is reduced, ${ }^{3}$ the bond length is $2.31 \AA$. The $\mathrm{Cu}-\mathrm{S}(\mathrm{Cys})$ bond length for $\mathrm{Cu}_{\mathrm{A}}$ in both oxidized and reduced cytochrome $c$ oxidase is close to the $\mathrm{Cu}-\mathrm{S}(\mathrm{Cys})$ bond length in reduced plastocyanin of $2.25 \AA$ (44). In contrast, the $\mathrm{Cu}-\mathrm{S}(\mathrm{Cys})$ bond length in oxidized plastocyanin is $2.1 \AA$. This similarity between the $\mathrm{Cu}-\mathrm{S}$ (Cys) bond length in oxidized cytochrome $c$ oxidase and reduced plastocyanin, as well as the lack of significant change of the $\mathrm{Cu}-\mathrm{S}$ bond length upon reduction of cytochrome $c$ oxidase, is strong evidence that $\mathrm{Cu}_{\mathrm{A}}$ is ligated by two cysteinyl sulfurs and is formally $\mathrm{Cu}(\mathrm{I})$ in the oxidized enzyme, in accordance with the main features of the Chan model.

In search of an appropriate model for the $\mathrm{Cu}_{\mathrm{A}}$ site, we have recently noted with interest the properties of a substituted horse liver alcohol dehydrogenase wherein the catalytic zinc has been replaced by copper. X-ray crystallographic studies of native horse liver alcohol dehydrogenase show that the catalytic zinc ion is coordinated in a distorted tetrahedral geometry by two cysteinyl sulfurs, one histidyl imidazole nitrogen, and a water or hydroxyl oxygen, and that this center is buried in a deep hydrophobic pocket of the protein (45). This catalytic $\mathrm{Zn}$ (II) can be reversibly removed and Cu(II) inserted into the site, resulting in a copper center with EPR and optical properties similar to those of the blue coppers (46, 47). Interestingly, when the NADH cofactor is bound to the copper-substituted protein (presumably at its specific binding site near to, but separate from, the catalytic site (45)), the EPR spectrum exhibited by the copper center is very similar to the EPR spectrum exhibited by $\mathrm{Cu}_{\mathrm{A}}$ of oxidized cytochrome $c$ oxidase, both with respect to observed $g$ values and with respect to the unusually low copper hyperfine coupling discussed earlier. More detailed EPR, ENDOR, and extended xray absorption fine structure studies of this model copper protein will prove useful in further testing the Chan model of the $\mathrm{Cu}_{\mathrm{A}}$ center in cytochrome $c$ oxidase.

Acknowledgments-We are grateful to Drs. Hal Beilan and Doug

${ }^{3}$ R. A. Scott, S. P. Cramer, R. W. Shaw, and H. Beinert, unpublished results. 
Brown for their technical assistance in the synthesis of labeled cysteine in the early stages of this work. We are indebted to Dr. Savely Goldin for assistance in performing the ENDOR measurements and to Dr. Randall Morse for helpful discussions.

\section{REFERENCES}

1. Beinert, H., Griffiths, D. E., Wharton, D. C., and Sands, R. H. (1962) J. Biol. Chem. 237, 2337-2346

2. Beinert, H., and Palmer, G. (1964) J. Biol. Chem. 239, 1221-1227

3. Aasa, R., Albracht, S. P. J., Falk, K.-E., Lanne, B., and Vänngard, T. (1976) Biochim. Biophys. Acta 422, 260-272

4. Tweedle, M. F., Wilson, L. J., García-Iñiguez, L., Babcock, G. T., and Palmer, G. (1978) J. Biol. Chem. 253, 8065-8071

5. Peisach, J., and Blumberg, W. E. (1974) Arch. Biochem. Biophys. 165, 691-708

6. Chan, S. I., Bocian, D. F., Brudvig, G. W., Morse, R. H., and Stevens, T. H. (1978) in Frontiers of Biological Energetics (Dutton, P. L., Leigh, J. S., Jr., and Scarpa, A., eds) Vol. 2, pp. 883-888, Academic Press, New York

7. Chan, S. I., Bocian, D. F., Brudvig, G. W., Morse, R. H., and Stevens, T. H. (1979) in Cytochrome Oxidase (King, T. E., Orii, Y., Chance, B., and Okunuki, K., eds) pp. 177-188, Elsevier, Amsterdam

8. Hemmerich, P. (1966) in The Biochemistry of Copper (Peisach, J., Aisen, P., and Blumberg, W. E., eds) pp. 15-34, Academic Press, New York

9. Greenaway, F. T., Chan, S. H. P., and Vincow, G. (1977) Biochim. Biophys. Acta 490, 62-78

10. Hoffman, B. M., Roberts, J. E., Swanson, M., Speck, S. H., and Margoliash, E. (1980) Proc. Natl. Acad. Sci. U.S. A. 77, 14521456

11. Fee, J. A. (1975) Struct. Bonding (Berlin) 23, 1-60

12. Wharton, D. C. (1974) Metal Ions Biol. Systems 3, 157-181

13. Gibson, Q. H., and Greenwood, C. (1965) J. Biol. Chem. 240 , 2694-2698

14. Hu, V. W., Chan, S. I., and Brown, G. S. (1977) Proc. Natl. Acad. Sci. U. S. A. 74, 3821-3825

15. Powers, L., Blumberg, W. E., Chance, B., Barlow, C. H., Leigh, J. S., Jr., Smith, J., Yonetani, T., Vik, S., and Peisach, J. (1979) Biochim. Biophys. Acta 546, 520-538

16. Chan, S. I., Brudvig, G. W., Martin, C. T., and Stevens, T. H. (1982) in Electron Transport and Oxygen Utilization (Ho, C., ed) pp. 171-177, Elsevier, Amsterdam

17. Crawhall, J. C., and Elliot, D. V. (1951) J. Chem. Soc. 2071-2073

18. Beilan, $\mathrm{H}$. (1977) $\mathrm{Ph} . \mathrm{D}$. thesis, University of California, Berkeley

19. Fink, G. R. (1970) Methods Enzymol. 17, 59-78

20. Difco Manual (1953) Difco Laboratories, Detroit, p. 251

21. Tzagoloff, A. (1969) J. Biol. Chem. 244, 5020-5026

22. Shakespeare, P. G., and Mahler, H. R. (1971) J. Biol. Chem. 246, 7649-7655
23. Lowry, O. H., Rosebrough, N. J., Farr, A. L., and Randall, R. J. (1951) J. Biol. Chem. 193, 265-275

24. Ozawa, T., Okumura, M., and Yagi, K. (1975) Biochem. Biophys. Res. Commun. 65, 1102-1107

25. Godinot, C., and Gautheron, D. C. (1979) Methods Enzymol. 55, 112-124

26. Van Gelder, B. F. (1966) Biochim. Biophys. Acta 118, 36-46

27. Morrison, M., and Horie, S. (1965) Anal. Biochem. 12, 77-82

28. Scholes, C. P. (1979) in Multiple Electron Resonance Spectroscopy (Dorio, M. M., and Freed, J. H., eds) pp. 297-329, Plenum Press, New York

29. Van Camp, H. L., Scholes, C. P., and Mulks, C. F. (1976) J. Am Chem. Soc. 98, 4094-4098

30. Van Camp, H. L., Wei, Y. H., Scholes, C. P., and King, T. E. (1978) Biochim. Biophys. Acta 537, 238-246

31. Wikström, M., Krab, K., and Saraste, M. (1981) Cytochrome Oxidase, pp. 17-23, Academic Press, London

32. Lemberg, M. R. (1969) Physiol. Rev. 49, 48-121

33. Mason, T. L., Poyton, R. O., Wharton, D. C., and Schatz, G. (1973) J. Biol. Chem. 248, 1346-1354

34. Froncisz, W., Scholes, C. P., Hyde, J. S., Wei, Y.-H., King, T. E., Shaw, R. W., and Beinert, H. (1979) J. Biol. Chem. 254, 74827484

35. Stevens, T. H., and Chan, S. I. (1981) J. Biol. Chem. 256, $1069-$ 1071

36. Brudvig, G. W. (1981) Ph.D. thesis, California Institute of Technology

37. Hartzell, C. R., and Beinert, H. (1974) Biochim. Biophys. Acto 368, 318-338

38. Krishnamoorthy, G., and Prabhananda, B. S. (1980) J. Phys. Chem. 84, 637-640

39. Robert, J. E., Brown, T. G., Hoffman, B. M., and Peisach, J. (1980) J. Am. Chem. Soc. 102, 825-829

40. Wertz, J. E., and Bolton, J. R. (1972) Electron Spin Resonance p. 124, McGraw-Hill, New York

41. Hadley, J. H., Jr., and Gordy, W. (1977) Proc. Natl. Acad. Sci. U. S. A. 74, 216-220

42. Abragam, A., and Bleaney, B. (1970) Electron Paramagnetic Resonance of Transition Ions, Oxford Press, London

43. Scott, R. A., Cramer, S. P., Shaw, R. W., Beinert, H., and Gray, H. B. (1981) Proc. Natl. Acad. Sci. U. S. A. 78, 664-667

44. Colman, P. M., Freeman, H. C., Guss, J. M., Murata, M., Norris, V. A., Ramshaw, J. A. M., and Venkatappa, M. P. (1978) Nature (Lond.) 272, 319-324

45. Eklund, H., Nordström, B., Zeppezauer, E., Söderlund, G., Ohlsson, I., Boiwe, T., Söderberg, B., Tapia, O., and Brändén, C. (1976) J. Mol. Biol. 102, 27-59

46. Maret, W., Dietrich, H., Ruf, H.-H., and Zeppezauer, M. (1980) $J$ Inorg. Biochem. 12, 241-253

47. Maret, W., Zeppezauer, M., Desideri, A., Morpurgo, L., and Rotilio, G. (1981) FEBS Lett. 136, 72-74 